\title{
ANALISIS PERMINTAAN DAN KEPUASAN PENUMPANG TERHADAP PELAYANAN BUS TRANSJAKARTA KORIDOR 10
}

\author{
Edric Yappo ${ }^{1}$ dan Najid ${ }^{2}$ \\ ${ }^{1}$ Program Studi Sarjana Teknik Sipil, Universitas Tarumanagara, Jl. Letjen S. Parman No.1 Jakarta \\ Email: edricyappo@yahoo.com \\ ${ }^{2}$ Program Studi Sarjana Teknik Sipil, Universitas Tarumanagara, Jl. Letjen S. Parman No.1 Jakarta \\ Email:najid2009@yahoo.com
}

\begin{abstract}
ABSTRAK
Pemprov DKI jakarta berusaha mengurangi kemacetan yang ada di jakarta dengan membangun moda transportasi massal yang biasa disebut transjakarta. Bus Transjakarta ini bertujuan untuk meningkatkan jumlah perjalanan penumpang dengan transportasi Bus yang lebih aman dan nyaman bagi penumpang Penelitian ini dilakukan untuk mengetahui sejauh mana kepuasan dan permintaan penumpang terhadap Bus Transjakarta pada jam puncak dan non-puncak. Data didapatkan dengan cara penyebaran kuesioner kuisioner kepada 100 responden, dan melalui survey langsung pada koridor 10. Dari hasil data tersebut akan di bandingkan dengan Standard Pelayanan Minimum. Berdasarkan hasil pengambilan data melalui survey on board di koridor 10, waktu tunggu kendaraan, waktu berhenti kendaraan dan kecepatan perjalanan pada saat waktu puncak dan non puncak lebih kecil atau sama dengan nilai SPM. Berdasarkan survey demand dan hasil tes korelasi, dapat disimpulkan bahwa semakin banyak jumlah koridor yang melewati halte busway maka semakin tinggi demand suatu halte.

Kata kunci: Bus Transjakarta, permintaan, kepuasan.
\end{abstract}

\section{PENDAHULUAN}

\section{Latar Belakang}

Jakarta merupakan ibu kota Republik Indonesia, dikenal juga sebagai kota metropolitan. Sebagai kota yang besar jakarta pasti memiliki banyak masalah, salah satunya adalah kemacetan lalu lintas. kemacetan ini muncul karena pertumbuhan kendaraan bermotor pribadi yang sangat pesat. Banyak dampak yang timbul akibat dari kemacetan, salah satunya dampak ekonomi. Dimulai dari borosnya penggunaan bahan bakar, dan juga keterlambatan delivery barang (barang konsumsi).

Ketersediaan transportasi umum merupakan salah satu penyebab kemacetan dimana faktor keamanan dan kenyamanan tidak mencukupi sehingga masyarakat umum lebih condong menggunakan kendaraan pribadi di banding transportasi umum.

Pemprov DKI jakarta berusaha mengurangi kemacetan yang ada di jakarta dengan membangun moda transportasi massal yang biasa disebut transjakarta. Bus Transjakarta ini bertujuan untuk meningkatkan jumlah perjalanan penumpang dengan transportasi Bus yang lebih aman dan nyaman bagi penumpang. Dan yang terpenting dengan diterapkannya sistem ini di Jakarta adalah untuk mengalihkan para pengguna kendaraan pribadi agar dapat berpindah menggunakan Bus Transjakarta sehingga dapat mengurangi kemacetan.

Dengan beralih dari kendaraan pribadi untuk menggunakan kendaraan umum, maka diharapkan polusi udara dan polusi suara yang ada di Jakarta juga dapat berkurang. Jika Bus Transjakarta memiliki kelebihan dibandingkan kendaraan umum lainnya, maka Bus Transjakarta juga memiliki kekurangan.Untuk itu, dilakukan studi dan penelitian untuk mengetahui kepuasan para pengguna sistem Transjakarta ini.

\section{Identifikasi Masalah}

Keinginan penumpang transjakarta akan ketersediaan fasilitas dan pelayanan di halte haruslah dipenuhi. Fasilitasfasilitas yang wajib memiliki kualitas yang baik seperti ; ruang tunggu, loket pembelian tiket, akses dari dan menuju ke halte, dll. Dan ada beberapa halte yang ditemukan mengalami penumpukan penumpang pada waktu puncak maksimal. 


\section{Batasan Masalah}

Karena terbatasnya waktu dan sumber daya lainnya, maka masalah pada penelitian dalam skripsi ini dibatasi sebagai berikut:

1. Aspek SPM yang dibahas hanyalah aspek pelayanan Koridor 10

2. Data didapat dengan cara melakukan tinjauan langsung ke lapangan dan meneliti pengguna bus Transjakarta dengan survei kuesioner.

\section{Rumusan Masalah}

Berdasarkan latar belakang yang telah di uraikan di atas, maka dapat dirumuskan masalah sebagai berikut :

1. Bagaimana tingkat kepuasan penumpang terhadap pelayanan Bus Transjakarta pada koridor 10?

2. Bagaimana permintaan penumpang terhadap bus Transjakarta pada saat jam puncak dan non puncak?

\section{Tujuan Penelitian}

Adapun tujuan dari pada penelitian ini, yaitu :

1. Menemukan kemungkinan masalah dan solusi dari pelaksanaan SPM.

2. Membandingkan harapan demand dan pelayanan Transjakarta koridor 10.

3. Menemukan permasalahan pada responden/pengguna busway.

\section{TINJAUAN PUSTAKA}

\section{Transportasi}

Menurut Salim (2000) transportasi adalah kegiatan pemindahan barang (muatan) dan penumpang dari suatu tempat ke tempat lain. Dalam transportasi ada dua unsur yang terpenting yaitu pemindahan/pergerakan (movement) dan secara fisik mengubah tempat dari barang (comoditi) dan penumpang ke tempat lain.

Menurut Miro (2005) transportasi dapat diartikan usaha memindahkan, mengerakkan, mengangkut, atau mengalihkan suatu objek dari suatu tempat ke tempat lain, di mana di tempat lain ini objek tersebut lebih bermanfaat atau dapat berguna untuk tujuan-tujuan tertentu

Sedangkan menurut Tamin (1997), prasarana transportasi mempunyai dua peran utama, yaitu sebagai alat bantu untuk mengarahkan pembangunan di daerah perkotaan dan sebagai prasarana bagi pergerakan manusia dan/atau barang yang timbul akibat adanya kegiatan di daerah perkotaan tersebut.

Manfaat atau kegunaan transportasi adalah sebagai berikut:

a. Efisiensi waktu. Dengan sarana dan prasarana transportasi yang baik dan teratur, masyarakat yang bekerja di ibu kota, baik yang bertempat tinggal di Jakarta maupun sekitarnya (Bogor, Depok, Tangerang, Bekasi) tentu akan sangat terbantu karena akan lebih mempersingkat waktu tempuh dan menghemat waktu perjalanan.

b. Efisiensi Biaya. Menyediakan kepada masyarakat suatu pelayanan pergerakan atau mobilitas yang aman, nyaman dan terjangkau bagi semua kalangan.

Efisiensi Jarak. Pemilihan rute yang akan ditempuh bervariasi, sehingga jarak yang ditempuh akan lebih pendek dan tentu akan lebih cepat. Ini berkaitan erat dengan efisiensi waktu dan efisiensi biaya.

\section{Masalah Transportasi}

Menurut Hobbs (1995), kemacetan disebabkan oleh tuntutan arus kedatangan kendaraan pada suatu sistem yang membutuhkan pelayanan yang mempunyai keterbatasan mengenai ketersediaan dan sistem pelayanannya.

Kepadatan di Jakarta yang semakin tinggi ini salah satunya disebabkan oleh penggunaan kendaraan pribadi yang semakin meningkat setiap harinya, tetapi tidak diikuti dengan pertumbuhan infrastruktur jalan. Maka dari itu pembangunan sarana transportasi umum yang memadai dan sesuai dengan permintaan pengguna jalan harus segera terealisasikan agar dapat memenuhi kebutuhan para pengguna jalan saat ini.

Ada istilah angkutan umum multimoda yang disebutkan Buchari (2010), menurutnya angkutan umum multimoda adalah serangkaian perjalanan yang menggunakan dua atau lebih moda yang terintegrasi, terhubung dengan transfer 
point, dan memiliki aturan, sehingga perjalanan menggunakan transportasi umum dapat dipersingkat baik dari segi waktu dan maupun ongkos transportasi.

Pemerintah DKI Jakarta telah mengoperasikan angkutan umum massal berbasis jalan (Bus Rapid Transit) yang dikenal dengan nama Transjakarta untuk mengatasi kepadatan yang terjadi. Namun, pada pelayanan Transjakarta masih terdapat beberapa kekurangan, seperti armada Transjakarta yang sering mengalami kerusakan, jumlah bus yang masih belum mencukupi, dan juga headway Transjakarta yang masih terlalu panjang.

\section{Transjakarta}

Ide pembangunan proyek Bus Rapid Transit di Jakarta muncul sekitar tahun 2001. Setelah itu ide ini ditindaklanjuti oleh Gubernur DKI Jakarta pada saat itu, Sutiyoso. Transjakarta mulai beroperasi pada tanggal 15 Januari 2004, ditandai dengan peresmian Koridor 1, dengan tujuan memberikan jasa angkutan yang lebih cepat, nyaman, dan terjangkau bagi seluruh warga Jakarta. Saat ini Transjakarta dikelola oleh PT Transportasi Jakarta yang merupakan Badan Layanan Umum (BLU) yang berada di bawah pengawasan Dinas Perhubungan Pemerintah Provinsi DKI Jakarta. BLU Transjakarta bertanggung jawab untuk mengelola Transjakarta yang meliputi perencanaan, pengoperasian, dan pemeliharaan.

Jumlah penumpang Transjakarta saat ini telah berbeda apabila dibandingkan dengan saat awal peluncurannya. Berdasarkan Widodo dan Rudyanto (2015), pertumbuhan penumpang Transjakarta mengalami penurunan setelah tahun 2011. Grafik penurunan jumlah pengguna Transjakarta dapat dilihat pada Gambar 1.

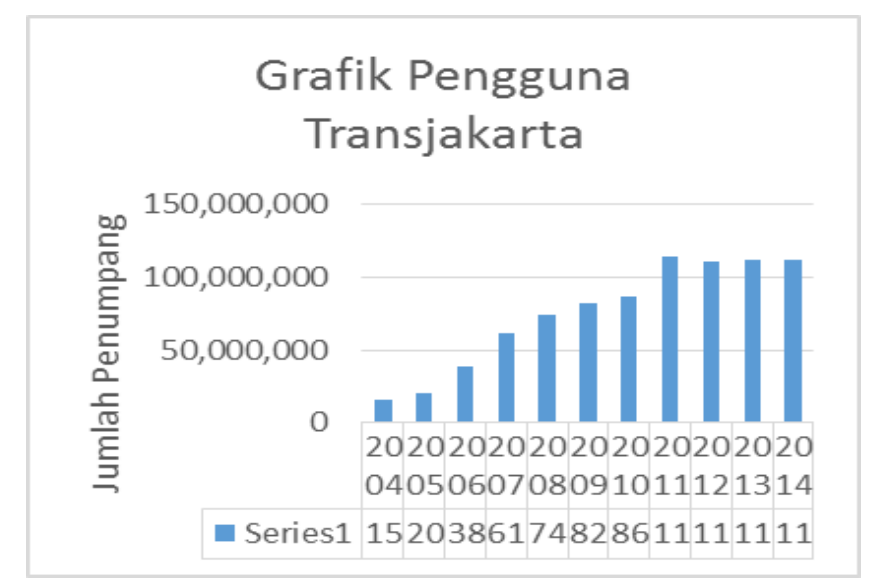

Gambar 1. Grafik pengguna transjakarta

(Sumber: Widodo dan Rudyanto, 2015)

Dalam pelaksanaannya, pemerintah provinsi DKI Jakarta melalui Peraturan Gubernur nomor 35 tahun 2014 telah mengeluarkan SPM Unit Pengelola Transjakarta Busway. Peraturan Gubernur tersebut harus menjadi landasan bagi operasional Transjakarta dan sekaligus dapat menjadi tolak ukur bagi kualitas pelayanan PT Transportasi Jakarta.

SPM PT Transportasi Jakarta memiliki beberapa aspek yang terdiri dari aspek keamanan, keselamatan, kenyamanan, keterjangkauan, kesetaraan, dan keteraturan. Dari enam aspek tersebut yang sering dikeluhkan oleh pengguna Transjakarta adalah aspek keteraturan. Aspek keteraturan ini memiliki beberapa variabel terukur seperti waktu tunggu kendaraan, kecepatan perjalanan kendaraan, waktu berhenti kendaraan di setiap halte, informasi pelayanan kendaraan, informasi waktu kedatangan kendaraan, akses keluar masuk di setiap halte, informasi halte yang akan dilayani kendaraan, ketepatan kedatangan dan keberangkatan, informasi gangguan perjalanan, dan sistem pembayaran.

\section{METODE PENELITIAN}

\section{Diagram Alir (Flow Chart)}

Untuk memastikan proses penelitian ini berjalan sistematis maka perlu dibuat bagan alir penelitian. Bagan alir dalam penelitian ini dapat dilihat pada Gambar 2 berikut. 


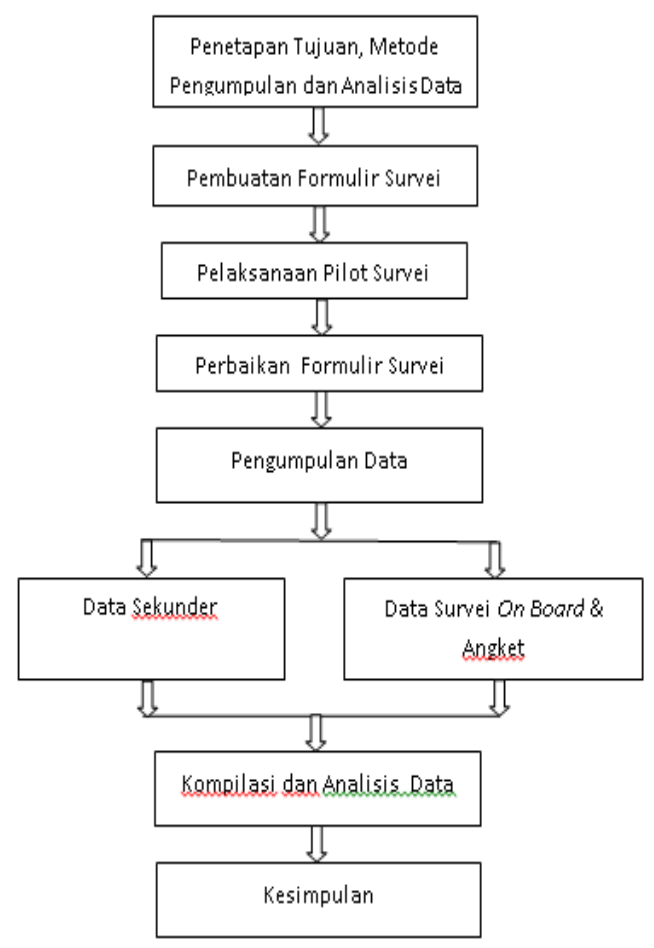

Gambar 2. Bagan alir tahapan penelitian

Adapun Metode yang digunakan dalam penulisan skripsi ini adalah:

1. Metode pengumpulan data sekunder dan analisis data sekunder.

2. Metode survei lapangan dengan langsung melihat fasilitas-fasilitas yang dimiliki oleh masing-masing halte yang diteliti.

\section{Metode Pengumpulan Data}

Metode survei dengan observasi lapangan dilakukan di halte transjakarta. Data primer dalam penelitian ini adalah survei pada pelayanan dan fasilitas dari seluruh halte pada koridor 10 transjakarta. Data sekunder yang diambil adalah jadwal keberangkatan dan jumlah penumpang.

\section{Kuesioner}

Banyak cara dalam menumpulkan data seperti wawancara, pengamatan, dokumentasi dan kuesioner. Dalam skripsi ini metode yang akan digunakan adalah menggunakan kuesioner dengan metode langsung maupun online.

\section{Kelebihan dan Kekurangan Kuisioner}

Kelebihan kuesioner sebagai berikut:

1. Tidak memerlukan hadirnya peneliti.

2. Dapat dibagikan secara serentak kepada responden.

3. Dapat dijawab oleh responden menurut kecepatannya masing-masing menurut waktu senggang responden.

4. Dapat dibuat anonim sehingga responden bebas, jujur dan tidak malu-malu menjawab.

5. Dapat dibuat berstandar sehingga semua responden dapat diberi pertanyaan yang benar-benar sama.

Kelemahan kuesioner adalah sebagai berikut:

1. Responden sering tidak teliti dalam menjawab sehingga ada pertanyaan yang terlewati tidak terjawab, padahal sukar diulangi diberikan kembali padanya.

2. Seringkali sukar dicari validitasnya.

3. Walaupun dibuat anonim, kadang-kadang responden sengaja memberikan jawaban yang tidak betul atau tidak jujur. 


\section{Metode Dasar Dalam Pembuatan Kuesioner}

Menurut Sandjaja dan Heriyanto (2006) dalam membuat sebuah kuesioner, untuk memperoleh butir kuesioner yang baik, ada beberapa hal yang harus diperhatikan, antara lain :

1. Setiap butir harus dibuat dengan bahasa yang jelas dan tidak mempunyai arti yang meragukan.

2. Pertanyaan mengacu pada tujuan penelitian atau berkaitan dengan permasalahan.

3. Butir pertanyaan atau pernyataan berkaitan dengan permasalahan yang ingin diteliti.

\section{Metode Analisis Data}

Statistika adalah suatu ilmu yang mempelajari tentang cara-cara pengumpulan data, penyajian daata, analisis dan interpretasi tentang data terseut. Seorang yang belajar statistika biasanya bekerja dengan data numerik yang berupa hasil cacahan ataupun hasil pengukuran, atau mungkin dengan data kategorik yang diklasifikasikan menurut kriteria tertentu. Setiap informasi yang tercatat dan terkumpul, baik numerik dan kategorik disebut pengamatan

Metode statistika adalah prosedur-prosedur yang digunakan dalam pegumpulan, penyajian, analisis, dan penafsiran data. Metode-metode tersebut dikelompokkan dalam dua kelompok besar, yaitu:

- Statistika Deskriptif

- Statistika Inferensial

Statistika deskriptif adalah metode yang berkaitan dengan pengumpulan dan penyajian suatu gugus data sehingga memberikan informasi yang berguna. Perlu kiranya dimengerti bahwa statistika deskriptif memberikan informasi hanya mengenai data yang dipunyai dan sama sekali tidak menarik kesimpulan yang lebih banyak dan lebih jauh dari data yang ada. Kegiatan memeriksa sifat-sifat penting dari data yang ada itu disebut analisis data secara pemerian (deskripsi). Karenanya bagian statistika demikian dinamakan Statistika Deskriptif atau Statistika Perian. Penyusunan tabel, diagram, modus, kuartil, simpangan baku termasuk dalam kategori statistika deskriptif. Kegiatan itu dilakukan melalui:

a) Pendekatan aritmetika, yaitu pendekatan melalui pemeriksaan rangkuman nilai atau ukuran-ukuran penting dari data. Yang dimaksud rangkuman nilai di sini ialah penyederhanaan kumpulan nilai data yang diamati ke dalam bentuk nilainilai tertentu. Setiap rangkuman nilai ini disebut statistik. Jadi, statistik menerangkan sifat kumpulan data dalam bentuk nilai yang mudah dipahami, sedangkan statistika adalah suatu ilmu tentang sekumpulan konsep serta metode yang dapat digunakan untuk mengumpulkan, menyajikan dan menganalisis data serta menarik kesimpulan berdasar hasil analisis data tersebut.

b) Pendekatan geometrik, yaitu melalui penyajian data dalam bentuk gambar berupa grafik atau diagram. Kedua pendekatan mengakibatkan pembedaan dalam. penyajian datanya. Penyajian data pertama menekankan angkaangka dan yang kedua menekankan pada gambar.

Korelasi Pearson merupakan salah satu ukuran korelasi yang digunakan untuk mengukur kekuatan dan arah hubungan linier dari dua veriabel. Dua variabel dikatakan berkorelasi apabila perubahan salah satu variabel disertai dengan perubahan variabel lainnya, baik dalam arah yang sama ataupun arah yang sebaliknya. Harus diingat bahwa nilai koefisien korelasi yang kecil (tidak signifikan) bukan berarti kedua variabel tersebut tidak saling berhubungan. Mungkin saja dua variabel mempunyai keeratan hubungan yang kuat namun nilai koefisien korelasinya mendekati nol, misalnya pada kasus hubungan non linier. Dengan demikian, koefisien korelasi hanya mengukur kekuatan hubungan linier dan tidak pada hubungan non linier. Harus diingat pula bahwa adanya hubungan linier yang kuat di antara variabel tidak selalu berarti ada hubungan kausalitas, sebab-akibat.

\section{Mencari Mean Harapan dan Mean Persepsi}

Mean diperoleh dari menjumlahkan seluruh nilai dan membaginya dengan jumlah individu. Dalam istilah seharihari ia disebut angka rata-rata. Dalam statistik iakerapkali disebut Mean Aritmetik.(sumber : Prof. Drs. Sutrisno Hadi, MA,2000)

Untuk mendapatkan nilai dari Mean maka anda harus mencari tahu nilai tengah dan nilai hasil kali nilai tengah dengan frekuensi.

Rumus Mean yaitu:

$$
\frac{\sum f 1 \mathrm{x} 1}{\sum f 1}
$$

F1x1 adalah jumlah hasil dari nilai tengah di kali dengan frekuensi. F1 adalah jumlah frekuensi. 
Modus merupakan nilai yang paling sering muncul. Apabila ada data data frekuensi, jumlah dari suatu nilai dari kumpulan data, maka bisa memakai modus.

Untuk bisa melihat hasil akhir dari modus maka kita harus menentukan kelas pada tabel dengan memilih frekuensi yang paling banyak.

$$
\text { Modus }=t b+\left(\frac{\Delta F 1}{\Delta F 1+\Delta F 2}\right) p
$$

Keterangan:

$\mathrm{Tb}=$ Tepi bawah

$\Delta F 1=$ Frekuensi tertinggi dikurangi frekuensi diatasnya

$\Delta F 2=$ Frekuensi tertinggi dikurangi frekuensi dibawahnya

$\mathrm{P}=$ Interval

Median adalah cara untuk menentukan letak tengah data setelah data disusun menurut urutan nilainya. Simbol untuk median ini yaitu Me.

Median merupakan suatu nilai atau bilangan yang membatasi separo frekwensi bagian bawah distribusi dari separo bagian atas.Untuk menetapkan bilangan median, data kasar harus terlebih dahulu disusun menjadi array atau tabel distribusi.

$$
\text { Median }=t b+\left(\frac{\frac{n}{2}-F}{F m}\right) \mathrm{p}
$$

Keterangan :

$\mathrm{Tb}=$ Tepi bawah dari kelas $\mathrm{n} / 2$

$\mathrm{F}=$ Frekuensi kumulatif sebelum kelas median

$\mathrm{Fm}=$ Frekuensi kelas median

$\mathrm{P}=$ Interval

Kuisioner akan di sebar kepada responden untuk mencari mean persepsi dan harapan.

Untuk setiap pilihan yang akan dipilih oleh responden di setiap pertanyaan akan diberikan poin yang berbeda. Menggunakan 5 skala mulai dari sangat tidak setuju (STS), tidak setuju (TS), ragu-ragu (RR), setuju (S) dan sangat setuju (SS). Pilihan STS diberikan nilai 1, pilihan TS diberikan nilai 2, pilihan RR diberikan nilai 3, pilihan S diberikan nilai 4 dan pilihan SS diberikan nilai 5.

Menghitung mean harapan dan mean persepsi dapat dilakukan dengan cara mengalikan setiap jumlah jawaban tiap skala yang diperoleh dari seluruh responden untuk 1 pertanyaan (persepsi dan harapan) dengan skor nya masingmasing yang sudah di tentukan. Kemudian jumlahkan masing-masing skala.

Tabel 1. Contoh perhitungan persepsi

\begin{tabular}{ccccc}
\hline \multicolumn{5}{c}{ Persepsi } \\
\hline STS & TS & RR & S & SS \\
\hline $\mathrm{a}$ & $\mathrm{b}$ & $\mathrm{c}$ & $\mathrm{d}$ & $\mathrm{e}$ \\
\hline \multicolumn{5}{c}{$\mathrm{X}_{\mathrm{i}}=(\mathrm{ax} 1)+(\mathrm{bx} 2)+(\mathrm{cx} 3)+(\mathrm{dx} 4)+(\mathrm{ex} 5)$}
\end{tabular}

Tabel 2. Contoh perhitungan harapan

\begin{tabular}{ccccc}
\hline \multicolumn{5}{c}{ Harapan } \\
\hline STS & TS & RR & S & SS \\
\hline $\mathrm{a}$ & $\mathrm{b}$ & $\mathrm{c}$ & $\mathrm{d}$ & $\mathrm{e}$ \\
\hline & $\mathrm{Yi}=(\mathrm{ax} 1)+(\mathrm{bx} 2)+(\mathrm{cx} 3)+(\mathrm{dx} 4)+(\mathrm{ex} 5)$ &
\end{tabular}


Maka akan mendapatkan mean persepsi (Xi) dan mean harapan (Yi) dari setiap poin pertanyaan.

Keterangan:

$\mathrm{Xi}=$ Skor penilaian kinerja perusahaan

Yi = Skor penilaian kepentingan pelanggan

Setelah mencari hasil $\mathrm{Xi}$ dan Yi dari masing-masing item pertanyaan, lalu hasil tersebut dibagi oleh jumlah responden yang menjawab kuesioner tersebut. Untuk mendapatkan harga $\overline{X i}$ dan $\overline{Y i}$.

\section{PENGUMPULAN DAN ANALISIS DATA}

\section{Pengumpulan Data}

Menyajikan data yang diperoleh dari survei secara langsung dan kuesioner responden yang disebar kepada pengguna moda trasportasi Bus Transjakarta. Data responden yang diambil sebanyak 100 orang. Data responden didapatkan dengan penyebaran kuesioner langsung dan melalui internet. Berikut merupakan contoh dari data responden.

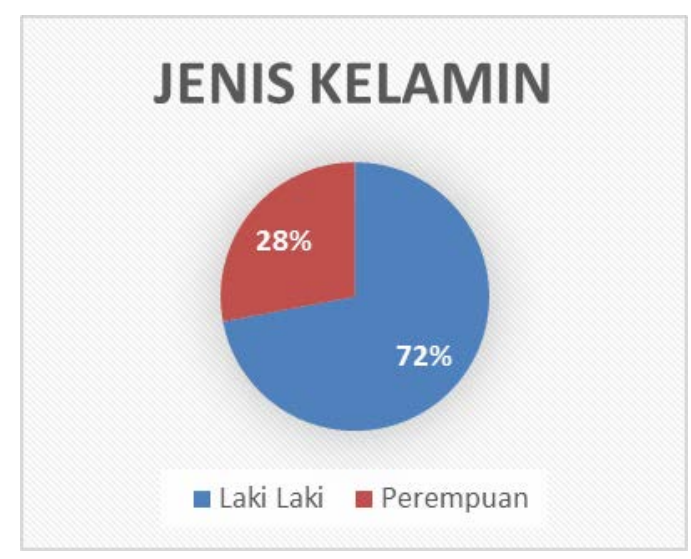

Gambar 3. Data jenis kelamin responden

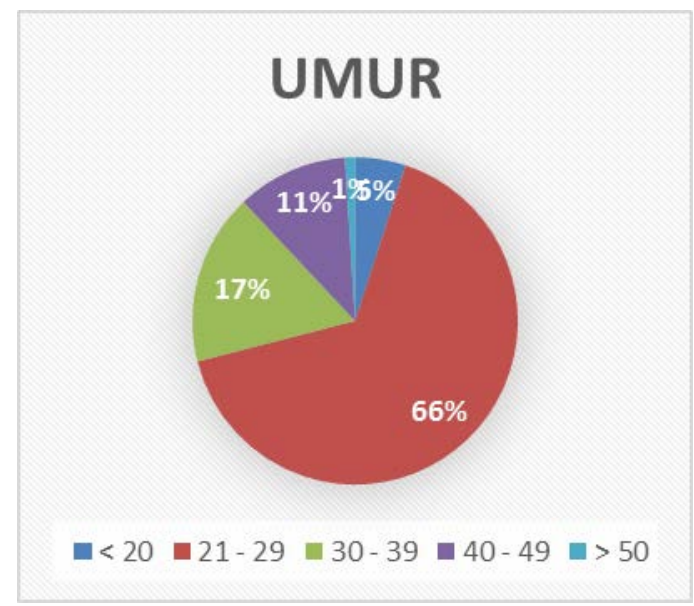

Gambar 4. Data usia responden 


\section{PENDIDIKAN}

TERAKHIR

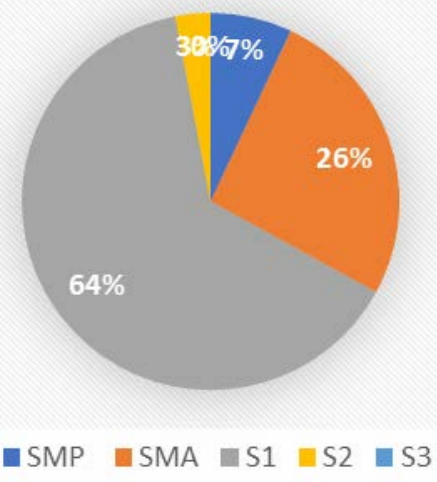

Gambar 5. Data pendidikan responden

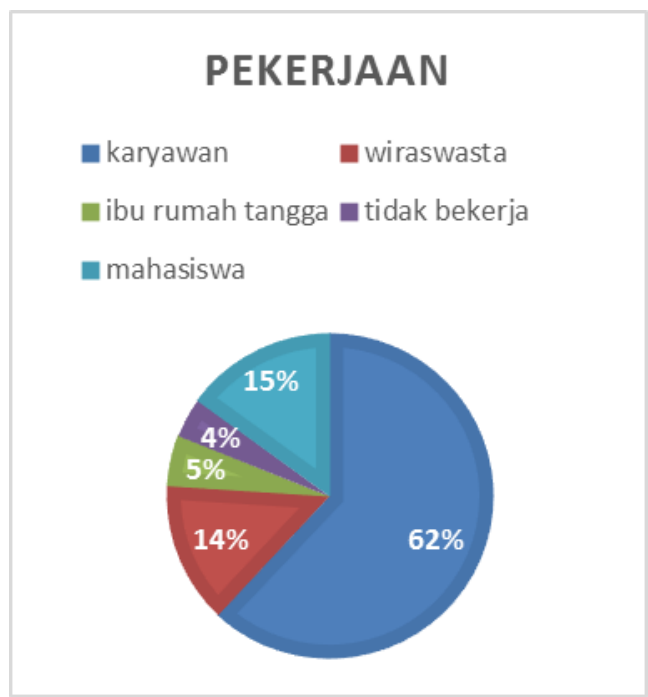

Gambar 6. Data pekerjaan responden

\section{Tes Korelasi}

Hasil tes korelasi akan diberikan pada tabel 3 dan tabel 4 berikut.

Tabel 3. Hasil korelasi tes jumlah koridor dan jumlah permintaan

\begin{tabular}{|c|c|c|c|}
\hline & & Jumlah Koridor & $\begin{array}{c}\text { Jumlsh_Permint } \\
\text { gan } \\
\end{array}$ \\
\hline \multirow[t]{3}{*}{ Jumlsh_Koridor } & Pearson Correlation & 1 & .977 \\
\hline & Sig. (2-tailed) & & .004 \\
\hline & $\mathrm{N}$ & 5 & 5 \\
\hline \multirow[t]{3}{*}{ Jumlsh_Permintsan } & Pearson Correlation & $977^{*}$ & 1 \\
\hline & Sig. (2-tailed) & .004 & \\
\hline & $\mathrm{N}$ & 5 & 5 \\
\hline
\end{tabular}

- Correlation is significant at the 0.01 level $(2$-tailed). 
Tabel 4. Hasil korelasi tes jumlah permintaan dan level

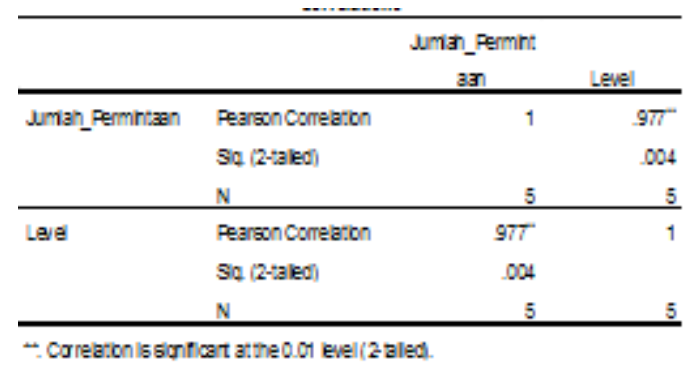

\section{PENUTUP}

\section{Kesimpulan}

Berdasarkan penelitian yang dilakukan, maka dapat diambil kesimpulan sebagai berikut:

1. Berdasarkan hasil pengambilan data melalui survey on board di koridor 10, waktu tunggu kendaraan,waktu berhenti kendaraan dan kecepatan perjalanan pada saat waktu puncak dan non puncak lebih kecil atau sama dengan nilai SPM.

2. Pada koridor 10, waktu tunggu kendaraan terlama pada waktu puncak yaitu pada rute 9 (Cempaka Putih Pulomas Bypass) sebesar 306 detik (5.1 menit), Lama berhenti Terlama berada pada rute 1 (Tanjung Priok Enggano) yaitu 120 detik (2.14 menit), waktu Tempuh terlama pada rute 6 (Sunter Kelapa Gading - Yos Sudarso Kodamar) sebesar 239 detik (3.9 menit) sedangkan waktu headway kendaraan terlama pada rute 3 (Permai Koja - Walikota Jakarta Utara) sebesar 318 detik (5.3 menit)

3. Dari hasil penelitian tata guna lahan suatu halte sangat berpengaruh terhadap demand penumpang dimana halte dengan tata guna lahan pusat perkantoran, perdagangan, dan jasa skala kota memiliki demand lebih tinggi dari pada halte dengan tata guna lahan pusat stasiun terpadu, dan pusat pemerintahan kota.

4. Berdasarkan survey demand dan hasil tes korelasi, dapat disimpulkan bahwa jumlah koridor dan level sangat mempengaruhi demand pada suatu halte.

\section{Saran}

Berdasarkan hasil analisis, penulis mempunyai beberapa saran untuk lebih mengembangkan penelitian ini, antara lain:

1. Penelitian ini perlu di lakukan di koridor lain agar dapat membandingkan hasil on board dan persepsi pengguna Transjakarta dengan nilai SPM yang sudah ditentukan.

2. Penentuan Level dilakukan berdasarkan pengamatan visual sehingga dapat dilakukan survey tata guna lahan yang lebih detail agar mendapatkan hasil data yang lebih real.

\section{DAFTAR PUSTAKA}

Alma, Buchari. (2010). Kewirausahaan untuk Mahasiswa dan Umum. Alfabeta, Bandung.

Caraharian. (2017). Mencari Mean, Modus, Dan Median. http://caraharian.com/rumus-mean-medianmodus.html

Hobbs, F.D. (1995) Perencanaan dan Teknik Lalu Lintas. Penerbit Gadjah Mada University Press, Yogyakarta.

Miro, F. (2005). Perencanaan Transportasi untuk Mahasiswa, Perencana, dan Praktisi. Erlangga, Jakarta.

Nasution, M.N. (2004). Manajemen Jasa Terpadu. PT Ghalia Indonesia, Jakarta.

Salim, H.A. Abbas. (1993). Manajemen Transportasi. Jakarta: Raja Grafindo Persada

Sutrisno Hadi. (2000). Metodologi Research Jilid 3. Andi, Yogyakarta

Tamin, O.Z. (1997). Perencanaan dan Pemodelan Transportasi. Teknik Sipil Institut Teknologi Bandung, Bandung. 
